\title{
DIFFERENTIATED ANALYSIS OF OFFENSIVE ACTIONS BY FOOTBALL PLAYERS IN SELECTED MATCHES FROM THE EURO 2008
}

\author{
TOMASZ BURACZEWSKI ${ }^{1}$, LESZEK CICIRKO ${ }^{1}$, DAMIAN GAWLIK \\ ${ }^{1}$ The Josef Pilsudski University of Physical Education in Warsaw, Faculty of Physical Education and Sport \\ in Biała Podlaska, Department of Football and Volleyball
}

Mailing address: Tomasz Buraczewski, Faculty of Physical Education and Sport, Department of Football and Volleyball, 2 Akademicka Street, 21-500 Biała Podlaska, tel.: +48 502386478, fax: +48 833428800 ,

e-mail: burut@interia.pl

\begin{abstract}
Introduction. Football training should be organized in view of the requirements of contemporary sports and should be analyzed based on data obtained by observing the best teams in action. The goal of this study was to compare the frequency and effectiveness of selected tactical and technical actions performed by footballers from winning and losing teams in selected matches from the Euro 2008. Material and methods. The study involved close observation of performances by 166 players from 11 countries in 8 matches (Turkey-Czech Republic 3:2; Turkey-Switzerland 2:1; ItalyFrance 2:0; Holland-France 4:1; Sweden-Greece 2:0; Spain-Sweden 2:1; Germany-Portugal 3:2; Spain-Germany 1:0). The total amount of game observation time equaled 720 minutes. Analysis was conducted by repeatedly viewing DVDs of matches and coding the results on a detailed observational spreadsheet containing a detailed breakdown of offensive actions such as attempting goals, passing the ball or 1v1 attacking. Results and conclusions. Analysis showed that winning teams were more effective in seven out of eight indexes, i.e.: overall effectiveness in offense, effectiveness in attempting goals, overall effectiveness in passing, effectiveness in passing in easy situations, and effectiveness in 1v1 attacking. Losing teams were more effective solely in the index for passing in difficult situations.
\end{abstract}

Key words: football, soccer, Euro, European Football Championship, observation, winners, losers

\section{Introduction}

The contemporary game of football is characterized by the dominance of offensive actions based on rapid playmaking without receiving the ball, "full force" play connected with variable positions and tasks, and preventing the opponent from influencing the course of the game through "ball play". However, once possession of the ball has been lost, the players immediately seek to "rebuild" defensively and perform coordinated group actions aimed at recovering the ball from the rival [1].

The goal in observing how teams and players from the best clubs play football is to determine their underlying tactical and technical characteristics. These observations lead to important practical results: they show which elements are the most important in training footballers. The scope of the observations was both international [including 2, 3, 4, 5] and national [including $6,7,8,9,10]$.

In light of the above, there is no doubt that football training should be organized in view of the requirements of contemporary sports and should be analyzed based on data obtained by observing the best teams in action.

This study presents aspects of offensive play connected with kicking goals, passing the ball and 1v1 attacking as performed by the best teams playing during the $12^{\text {th }}$ European Football Championship in 2008.

The goal of the study was to compare the frequency and ef fectiveness of selected tactical and technical actions performed by footballers from winning and losing teams in selected matches from the Euro 2008. The questions to be investigated are as follows:

1. Do winning teams employ tactical and technical offensive actions more or less often than losing teams?

2. What levels of effectiveness in which offensive actions involving ball play influence winning a match?

\section{Material and methods}

The study examined footballers partici pating in the $12^{\text {th }}$ European Football Championship held in Austria and Switzerland in 2008. It involved close observation of performances by 166 players from 11 countries at 8 matches (Turkey-Czech Republic 3:2; Turkey-Switzerland 2:1; Italy-France 2:0; HollandFrance 4:1; Sweden-Greece 2:0; Spain-Sweden 2:1; GermanyPortugal 3:2; Spain-Germany 1:0). The total amount of game observation time equaled 720 minutes.

The study method consisted of systematic, external observation categorized using a standardized study tool: the observation spreadsheets proposed by Szwarc [10]. Observation was conducted by watching DVDs of football matches on TV. Analysis was conducted of the following tactical and technical actions: goal attempts, passes and 1v1 attacks, which were coded in light of 3 playing field zones (Fig. 1): $\mathbf{A}$ - defense (from the team's own goal line to around 35 meters), B - midfield (around 35-70 meters from their own goal line), $\mathbf{C}$ - attack (around 70 to 105 meters from their own goal line). 


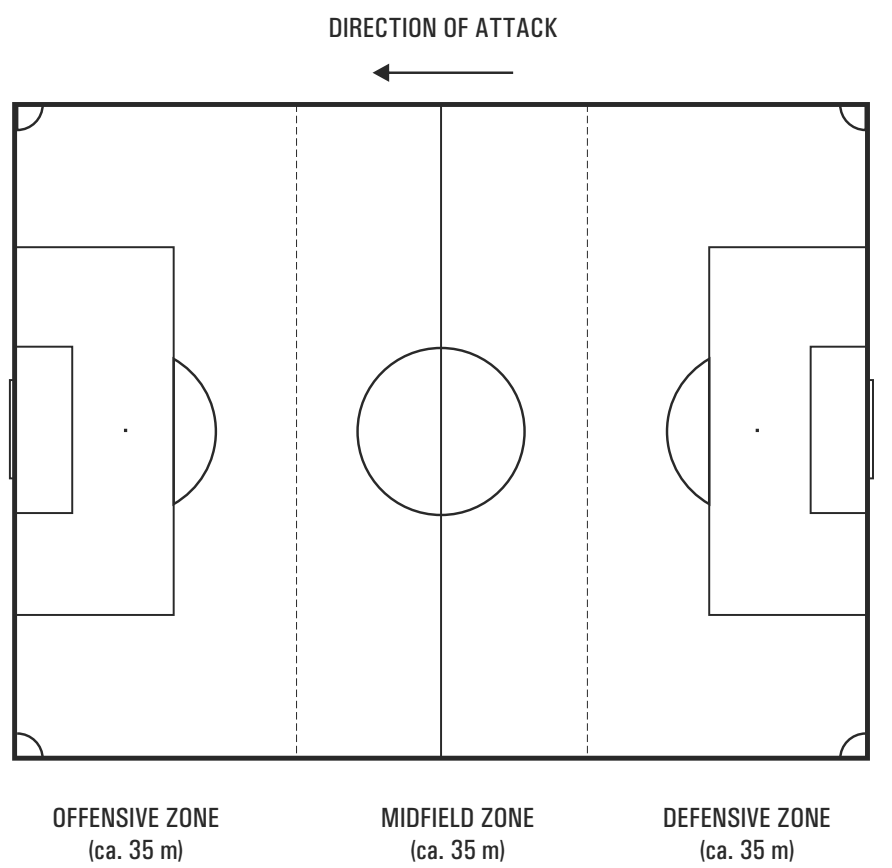

Figure 1. Division of field into zones

\section{Goal attempts}

Records were kept of goal attempts made by striking the ball with the foot or head in easy or difficult situations as follows: attempt using right foot, left foot and head. The quality of the attempts were also recorded: accurate attempt, goal scored; accurate attempt blocked by goalie; goal blocked by defender; inaccurate attempt.

Records were also kept of attempts involving direct and indirect free kicks, penalty kicks and corner kicks.

\section{Passing the ball}

Records were made of successful passes to teammates in easy $^{1}$ and difficult ${ }^{2}$ situations and in reference to the zone where the attempt took place (A, B, C). Goalies were also observed for accurate and inaccurate passes:

- by kicking the ball after receiving it from a teammate,

- by kicking it while in possession of the ball,

- by throwing it any number of ways,

- by drop kicking the ball from the goal for "accuracy".

\section{1v1 attacking}

$1 \mathrm{v} 1$ attacking is the sum total of the reactions and actions of a player who possess the ball and whose goal is to evade his rival and realize the principles of the game unhindered. 1v1 attacking was coded based on the zone where the action took place (A, $\mathrm{B}, \mathrm{C})$.

Statistical analysis was conducted using the program Statistica 6.0. The following descriptive statistics were used: arithmetic average, minimum value, maximum value, standard deviation, and Student's $t$ test for independent groups.

\section{Results}

Analysis of the data showed that losing teams made more goal attempts than winning teams: 117 vs. 112 attempts, respectively. Winning teams made an average of 14 attempts per game, while losing ones averaged 14.6 attempts. It can be assumed that this is a result of the winning team's controlling the course of the match and defending their "lead" (Tab. 1).

The players under observation scored 26 goals, of which 19 were by players on winning teams and 7 by those on losing teams, yielding an average of 2.37 goals per match for winners and only 0.87 for losers. Significant differences were detected here among groups of teams $(\mathrm{p}<0.05)$. Szwarc [12] and Buraczewski [13] noted similar results; both found that winning teams were more effective in making goal attempts.

There were 18 goal attempts made during set plays (11 times by winners, 7 by losers) leading to a single goal (Tab. 1). No significant statistical differences were detected here between winning and losing teams.

In analyzing unsuccessful goal attempts, it was noted that winning teams made 43 such attempts (5.4 times per match), while their opponents made 50 (6.2 times per match). Goalies prevented goal attempts by rivals 62 times; 30 of these were by goalies from winning teams and 32 from losing teams.

The analysis further shows that players from winning teams passed the ball more often than those from losing ones. The difference in the number of passes averaged 37.75 per match a relatively small difference. Analysis of passes made in zones $\mathrm{A}$ and $\mathrm{B}$ also failed to reveal any large differences. However, attention should be drawn to the large disparities in zone $\mathrm{C}$, where fluctuations averaged around 15 passes per match in the winning teams' favor. In both cases, no significant statistical differences were detected (Tab. 2).

Observation and analysis of successful and unsuccessful passes revealed that both kinds of passes were made more frequently by players from winning teams. From this it follows that winning players were in possession of the ball more often and therefore passed the ball to fellow players more frequently, although these pass attempts were not always successful. Examining successful pass attempts for each of the three zones reveals fundamental differences. Losing teams predominate in zone A; however, the number of passes made by winning teams increases as the distance to the opponent's goal decreases (an average difference of 25 passes in zone $\mathrm{B}$ and over 16 in zone $\mathrm{C}$ ). No major disparities were noted for unsuccessful pass attempts. Both groups of teams made similar numbers of unsuccessful pass attempts.

Analysis of pass attempts in easy situations shows that the results closely approximate those of accurate pass attempts. Winning teams dominate here as well. This was particularly evident in zones B and C, where the difference per match amounted to an average of 31 and 17 passes, respectively. Losing teams led the way in zone A by a small margin - nearly 5 passes more. Furthermore, analysis of successful pass attempts in easy situations revealed the following: in zone A losing teams had a slight lead, while in B and C there were major differences, with the winners leading by 30 and 16.5 passes, respectively. Only minimal differences were detected for unsuccessful pass attempts in easy situations (Tab. 3).

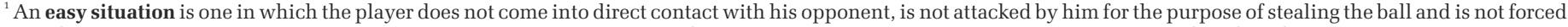

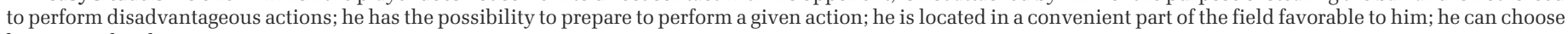
how to resolve the game situation.

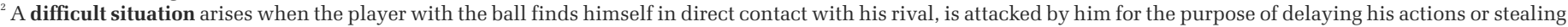
the ball, is in a situation with limited time and space or one directly involving a chance of losing the ball or scoring a goal.
} 
Table 1. Goal attempts made by players from "winning" and "losing" teams

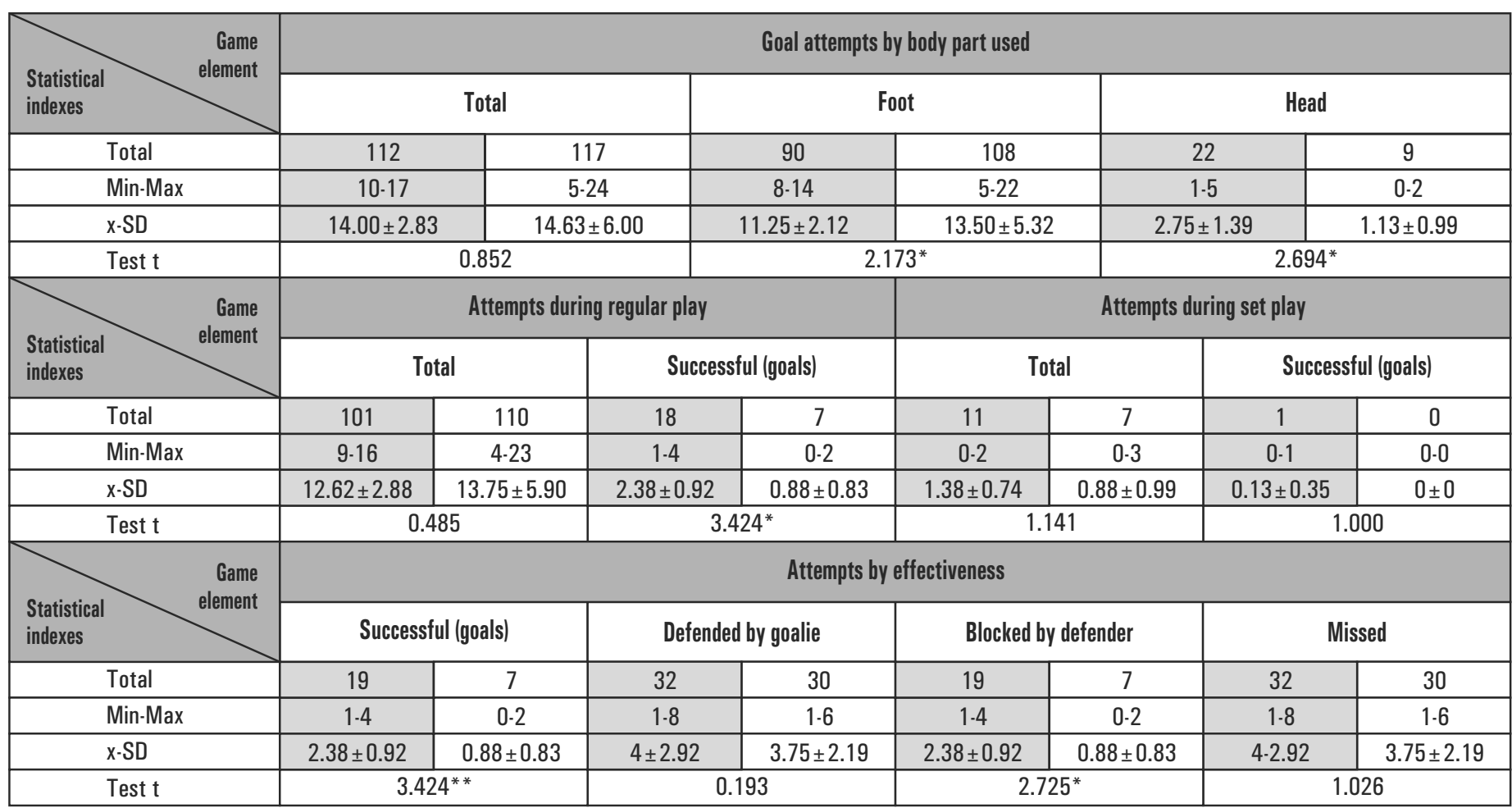

* indicates statistical significance $p<0.05 ;{ }^{* *} p<0.01$

successful

unsuccessful

Table 2. Pass attempts made by players from "winning" and "losing" teams

\begin{tabular}{|c|c|c|c|c|c|c|c|c|}
\hline \multirow{3}{*}{$\begin{array}{l}\text { Statistical } \\
\text { indexes }\end{array}$} & \multicolumn{8}{|c|}{ Total for all pass attempts } \\
\hline & \multicolumn{2}{|c|}{ Total } & \multicolumn{2}{|c|}{ Zone A } & \multicolumn{2}{|c|}{ Zone B } & \multicolumn{2}{|c|}{ Zone C } \\
\hline & $3586=$ & 3284- & 597 & 667 & 2112 & 1891 & 730 & 611 \\
\hline Min-Max & $314-645$ & $289-521$ & $34-107$ & $49-119$ & $160-439$ & $155-308$ & $51-132$ & $38-114$ \\
\hline$x-S D$ & $448.25 \pm 100.12$ & $410.5 \pm 84.95$ & $74.63 \pm 22.24$ & $83.38 \pm 27.36$ & $264 \pm 90.94$ & $236.38 \pm 56.63$ & $91.25 \pm 26.72$ & $76,38 \pm 27.60$ \\
\hline Test $\mathrm{t}$ & \multicolumn{2}{|c|}{0.813} & \multicolumn{2}{|c|}{0.702} & \multicolumn{2}{|c|}{0.729} & \multicolumn{2}{|c|}{1.095} \\
\hline \multirow{2}{*}{$\begin{array}{l}\text { Statistical } \\
\text { indexes }\end{array}$} & \multicolumn{8}{|c|}{ Total for all successful pass attempts } \\
\hline & \multicolumn{2}{|c|}{ Total } & \multicolumn{2}{|c|}{ Zone A } & \multicolumn{2}{|c|}{ Zone B } & \multicolumn{2}{|c|}{ Zone C } \\
\hline Total & $2876=$ & 2591= & 499 & 581 & 1790 & 1589 & 526 & 395 \\
\hline Min-Max & $208-573$ & $184-421$ & $21-100$ & $38-108$ & $114-392$ & $110-268$ & 41.92 & 27.76 \\
\hline$x-S D$ & $359.5 \pm 107.04$ & $323.88-88.98$ & $62.38 \pm 23.16$ & $72.63 \pm 25.96$ & $223.75 \pm 86.82$ & $198.63 \pm 59.44$ & $65.75 \pm 16.14$ & $49.38 \pm 20.46$ \\
\hline Test $\mathrm{t}$ & \multicolumn{2}{|c|}{0.724} & \multicolumn{2}{|c|}{0.833} & \multicolumn{2}{|c|}{0.675} & \multicolumn{2}{|c|}{$2.212^{*}$} \\
\hline Game & \multicolumn{8}{|c|}{ Total for all unsuccessful pass attempts } \\
\hline indexes & \multicolumn{2}{|c|}{ Total } & \multicolumn{2}{|c|}{ Zone A } & \multicolumn{2}{|c|}{ Zone B } & \multicolumn{2}{|c|}{ Zone C } \\
\hline Total & 722 & 682 & 97 & 91 & 307 & 310 & 222 & 190 \\
\hline Min-Max & $67-116$ & $72 \cdot 105$ & $7-21$ & $2 \cdot 21$ & 21.49 & $30-45$ & $10-40$ & $9-34$ \\
\hline$x-S D$ & $90.25 \pm 16.71$ & $85.25 \pm 11.36$ & $12.13 \pm 4.49$ & $11.38 \pm 5.63$ & $38.38 \pm 12.32$ & $38.75 \pm 4.53$ & $27.75 \pm 11.04$ & $23.75 \pm 9.30$ \\
\hline Test $\mathrm{t}$ & \multicolumn{2}{|c|}{0.700} & \multicolumn{2}{|c|}{$\frac{1}{0.295}$} & \multicolumn{2}{|c|}{$\frac{1}{0.081}$} & \multicolumn{2}{|c|}{0.922} \\
\hline
\end{tabular}

* indicates statistical significance $p<0.05$

- Total includes numbers for all passes in zones A, B and C and goalie kicks

successful

unsuccessful 
Table 3. Pass attempts made in easy situations by players from "winning" and "losing" teams

\begin{tabular}{|c|c|c|c|c|c|c|c|c|}
\hline \multirow{3}{*}{$\frac{\begin{array}{c}\text { Statistical } \\
\text { indexes }\end{array}}{\text { Total }}$} & \multicolumn{8}{|c|}{ Total for all pass attempts in easy situations } \\
\hline & \multicolumn{2}{|c|}{ Total } & \multicolumn{2}{|c|}{ Zone A } & \multicolumn{2}{|c|}{ Zone B } & \multicolumn{2}{|c|}{ Zone C } \\
\hline & 3067: & 2709. & 448 & 495 & 1854 & 1606 & 615 & 479 \\
\hline Min-Max & 241.569 & $225-458$ & $23-91$ & $24-96$ & $120-403$ & $125-281$ & $44-115$ & $18-98$ \\
\hline$x-S D$ & $383.38 \pm 96.25$ & $338.63 \pm 98.19$ & $56 \pm 19.89$ & $61.88 \pm 27.28$ & $231.75 \pm 89.32$ & $200.75 \pm 63.64$ & $76.88 \pm 21.85$ & $59.88 \pm 27.86$ \\
\hline Test $\mathrm{t}$ & \multicolumn{2}{|c|}{0.921} & \multicolumn{2}{|c|}{0.492} & \multicolumn{2}{|c|}{0.800} & \multicolumn{2}{|c|}{$2.169^{*}$} \\
\hline & \multicolumn{8}{|c|}{ Total for all successful pass attempts in easy situations } \\
\hline indexes & \multicolumn{2}{|c|}{ Total } & \multicolumn{2}{|c|}{ Zone A } & \multicolumn{2}{|c|}{ Zone B } & \multicolumn{2}{|c|}{ Zone C } \\
\hline Total & 2570 & 2230: & 400 & 454 & 1645 & 1405 & 467 & 335 \\
\hline Min-Max & $180-510$ & $152-393$ & $13-86$ & $19-88$ & $97-369$ & $97-253$ & $36-82$ & $15-71$ \\
\hline$x-S D$ & $321.25 \pm 97.65$ & $278.75 \pm 100.47$ & $50 \pm 21.17$ & $56.75 \pm 27.41$ & $205.63 \pm 85.53$ & $175.63 \pm 65.85$ & $58.38 \pm 13.49$ & $41.88 \pm 21.38$ \\
\hline Test $\mathrm{t}$ & \multicolumn{2}{|c|}{0.858} & \multicolumn{2}{|c|}{0.551} & \multicolumn{2}{|c|}{0.786} & \multicolumn{2}{|c|}{$2.199^{*}$} \\
\hline & \multicolumn{8}{|c|}{ Total for all unsuccessful pass attempts in easy situations } \\
\hline indexes & \multicolumn{2}{|c|}{ Total } & \multicolumn{2}{|c|}{ Zone A } & \multicolumn{2}{|c|}{ Zone B } & \multicolumn{2}{|c|}{ Zone C } \\
\hline Total & 504" & 479. & 48 & 41 & 209 & 201 & 148 & 153 \\
\hline Min-Max & 51.87 & $46-73$ & $2 \cdot 12$ & 0.10 & $19-34$ & $12-31$ & $8-33$ & $3-30$ \\
\hline$x-S D$ & $63 \pm 12.55$ & $59.88 \pm 9.14$ & $6 \pm 3.55$ & $5.13 \pm 3.40$ & $26.13 \pm 5.54$ & $25.13 \pm 6.15$ & $18.5 \pm 8.62$ & $19.13 \pm 9.13$ \\
\hline Test $t$ & \multicolumn{2}{|c|}{12.55} & \multicolumn{2}{|c|}{9.14} & \multicolumn{2}{|c|}{3.55} & \multicolumn{2}{|c|}{3.40} \\
\hline
\end{tabular}

* indicates statistical significance $\mathrm{p}<0.05$

- Total includes numbers for all passes in zones A, B and C and goalie kicks

successful

unsuccessful

Table 4. Pass attempts made in difficult situations by players from "winning" and "losing" teams

\begin{tabular}{|c|c|c|c|c|c|c|c|}
\hline \multirow{3}{*}{$\begin{array}{l}\text { Statistical } \\
\text { indexes }\end{array}$} & \multicolumn{7}{|c|}{ Total for all pass attempts in difficult situations } \\
\hline & Total & \multicolumn{2}{|c|}{ Zone A } & \multicolumn{2}{|c|}{ Zone B } & \multicolumn{2}{|c|}{ Zone C } \\
\hline & 574- & 149 & 176 & 257 & 295 & 115 & 123 \\
\hline Min-Max & $46-110$ & 11.24 & $10-34$ & $10-43$ & $12-63$ & $3-38$ & $9-24$ \\
\hline$x-S D$ & $71.75 \pm 21.10$ & $18.63 \pm 4.34$ & $22 \pm 7.93$ & $32.13 \pm 10.22$ & $36.88 \pm 17.10$ & $14.38 \pm 10.78$ & $15.38 \pm 5.04$ \\
\hline Test $\mathrm{t}$ & 1.266 & \multicolumn{2}{|c|}{$2.152^{*}$} & \multicolumn{2}{|c|}{0.848} & \multicolumn{2}{|c|}{0.238} \\
\hline \multirow{2}{*}{$\begin{array}{l}\text { Statistical } \\
\text { indexes }\end{array}$} & \multicolumn{7}{|c|}{ Total for all successful pass attempts in difficult situations } \\
\hline & Total & \multicolumn{2}{|c|}{ Zone A } & \multicolumn{2}{|c|}{ Zone B } & \multicolumn{2}{|c|}{ Zone C } \\
\hline Total & 370 . & 99 & 127 & 145 & 184 & 59 & 60 \\
\hline Min-Max & $32-83$ & $8-15$ & $8-27$ & $7-23$ & $9-43$ & $1-26$ & $3-14$ \\
\hline$x-S D$ & $46.25 \pm 19.49$ & $12.38 \pm 2.67$ & $15.88 \pm 6.45$ & $18.13 \pm 4.91$ & $23 \pm 12.38$ & $7.38 \pm 8.12$ & $7.5 \pm 4.14$ \\
\hline Test $\mathrm{t}$ & $2.221^{*}$ & \multicolumn{2}{|c|}{$2.271^{*}$} & \multicolumn{2}{|c|}{$2.172^{*}$} & \multicolumn{2}{|c|}{0.039} \\
\hline & \multicolumn{7}{|c|}{ Total for all unsuccessful pass attempts in difficult situations } \\
\hline indexes & Total & \multicolumn{2}{|c|}{ Zone A } & \multicolumn{2}{|c|}{ Zone B } & \multicolumn{2}{|c|}{ Zone C } \\
\hline Total & 203: & 50 & 49 & 112 & 91 & 56 & 63 \\
\hline Min-Max & $17-32$ & $2 \cdot 9$ & $2-11$ & $3-26$ & $3-17$ & $2 \cdot 12$ & $4-11$ \\
\hline$x-S D$ & $25.38 \pm 5.07$ & $6.25 \pm 2.55$ & $6.13 \pm 2.80$ & $14 \pm 7.62$ & $11.38 \pm 4.81$ & $7 \pm 3.82$ & $7.88 \pm 2.80$ \\
\hline Test $t$ & 0.618 & \multicolumn{2}{|c|}{0.093} & \multicolumn{2}{|c|}{0.853} & \multicolumn{2}{|c|}{$\frac{1}{0.523}$} \\
\hline
\end{tabular}

* indicates statistical significance $\mathrm{p}<0.05$

- Total includes numbers for all passes in zones A, B and C and goalie kicks

successful

unsuccessful 
Analysis of pass attempts in difficult situations, i.e. those involving active interference on the part of an opponent, reveals no significant differences between groups. Players from losing teams led the way both in the total number of pass attempts and the number of attempts per zone (A, B, C).

Analysis of successful pass attempts in difficult situations reveals that players from losing teams led the way here as well for all three zones. The largest difference was detected in zone $B$ (a difference of nearly 5 passes per match). Players from winning teams made more unsuccessful pass attempts in difficult situations, although they did make a smaller number of unsuccessful passes to players in zone C (Tab. 4).

In summing up the analysis of the results of pass attempts in various situations, it can be shown that players from winning teams passed to their teammates more often. However, differences in this area were insignificant and should not be assumed to have had a decisive influence on the outcome of the match. passes per zone. On average, winning players won 13.25 duels, as opposed to 14.75 for losing ones. The number of $1 \mathrm{v} 1$ duels conducted differed depending on the zone and the position and skills of players engaged in the duel (Tab. 5).

\section{Discussion}

Table 6 lists effectiveness indexes for offensive play by winning and losing teams. Analysis of the data shows that winning teams scored higher in seven of the eight indexes, i.e.: overall effectiveness in offense (A), effectiveness in attempting goals $\left(\mathrm{S}_{\mathrm{S}}, \mathrm{S}_{\mathrm{G}}, \mathrm{S}_{\mathrm{SFG}}\right)$, overall effectiveness in passing $\left(\mathrm{P}_{\mathrm{O}}\right)$, effectiveness in passing in easy situations $\left(\mathrm{P}_{\mathrm{E}}\right)$, and effectiveness in $1 \mathrm{v} 1$ attacking. Losing teams were more effective solely in the index for passing in difficult situations $\left(\mathrm{P}_{\mathrm{T}}\right)$.

In analyzing the results obtained in studying overall offen-

Table 5. 1v1 attacking by players from "winning" and "losing" teams included in the study

\begin{tabular}{|c|c|c|c|c|c|c|c|c|}
\hline Game & \multicolumn{8}{|c|}{ 1v1 attacking duels won } \\
\hline indexes & \multicolumn{2}{|c|}{ Total } & \multicolumn{2}{|c|}{ Zone A } & \multicolumn{2}{|c|}{ Zone B } & \multicolumn{2}{|c|}{ Zone C } \\
\hline Total & 106 & 118 & 6 & 4 & 63 & 69 & 46 & 45 \\
\hline Min-Max & $3-31$ & $10-26$ & 0.2 & 0.2 & $3-13$ & $6-17$ & $2 \cdot 16$ & 1.9 \\
\hline$x-S D$ & $13.25 \pm 8.58$ & $14.75 \pm 5.04$ & $0.75 \pm 1.04$ & $0.5 \pm 0.76$ & $7.88 \pm 3.72$ & $8.63 \pm 3.58$ & $5.75 \pm 4.38$ & $5.63 \pm 2.72$ \\
\hline Test $\mathrm{t}$ & \multicolumn{2}{|c|}{0.426} & \multicolumn{2}{|c|}{0.552} & \multicolumn{2}{|c|}{0.411} & \multicolumn{2}{|c|}{0.069} \\
\hline
\end{tabular}

Losing players made more successful pass attempts, but they also led the way in unsuccessful ones. In simple situations, the winners were also shown to have led by a small margin, while falling behind in number and quality of passes in difficult situations. This may be due to the fierce, neck-and-neck competition that characterized the Euro 2008 finals.

Buraczewski [9] obtained different results indicating that the team representing Poland in the 2002 World Cup finals led the way in pass frequency and accuracy.

Analysis of $1 \mathrm{v} 1$ attacking showed that the balance of winning duels favored losing teams. However, the differences were slight, both with regard to the total number and the number of

Table 6. Gameplay effectiveness indexes for "winning" and "losing" teams included in the study

\begin{tabular}{|c|c|c|c|}
\hline \multicolumn{4}{|c|}{ Gameplay effectiveness indexes } \\
\hline \multirow[b]{2}{*}{ Type } & \multirow[b]{2}{*}{ Symbol } & \multicolumn{2}{|c|}{ Value (\%) } \\
\hline & & $\begin{array}{c}\text { Winners } \\
N=8\end{array}$ & $\begin{array}{c}\text { Losers } \\
\mathrm{N}=8\end{array}$ \\
\hline Overall effectiveness in offense & A & 79.31 & 76.53 \\
\hline Overall effectiveness in goal attempts & $\mathrm{S}_{\mathrm{S}}$ & 16.96 & 5.98 \\
\hline $\begin{array}{l}\text { Overall effectiveness in attempting } \\
\text { goals during regular play }\end{array}$ & $\mathrm{S}_{6}$ & 17.82 & 6.36 \\
\hline $\begin{array}{l}\text { Overall effectiveness in attempting } \\
\text { goals during set play }\end{array}$ & $\mathrm{S}_{\mathrm{SFG}}$ & 9.09 & 0 \\
\hline $\begin{array}{l}\text { Overall effectiveness in passing } \\
\text { the ball }\end{array}$ & $P_{0}$ & 80.2 & 78.9 \\
\hline $\begin{array}{l}\text { Passing effectiveness in easy } \\
\text { situations }\end{array}$ & $P_{t}$ & 83.8 & 82.3 \\
\hline $\begin{array}{l}\text { Passing effectiveness in difficult } \\
\text { situations }\end{array}$ & $P_{T}$ & 59.06 & 64.46 \\
\hline Effectiveness in 1v1 attacking & $D_{1 v 1}$ & 52.74 & 52.68 \\
\hline
\end{tabular}

sive effectiveness, it should be pointed out that nearly identical results were obtained by Szwarc [14] in his study of winning players from selected games from the 1998 World Cup, the 2000 Africa Cup of Nations, the Euro 2000, the 2001 Copa América and the 2002 World Cup, which also showed that winning teams were more effective in offense, leading by nearly $3 \%$. He obtained similar results for comparisons of overall effectiveness in goal attempts, passing and 1v1 attacking.

\section{Conclusions}

1. No significant deviations were detected in the frequency with which winning and losing teams employ technical and tactical actions.

2. Players from winning teams were more effective at almost every aspect of offensive play included in the study. The largest differences concerned the effectiveness of goal attempts made during regular play and set play.

\section{Literature}

1. Szwarc A. (2007). Effective action in selected fragments from team sports - a football case study. Gdańsk: AWFiS Gdańsk. [in Polish]

2. Kunh W. (2005). Changes in professional soccer: a qualitative and quantitative study. In T. Reilly, J. Cabri, D. Araujo (Eds.), Science and football (pp. 179-193). London, New York: V. Routledge, Taylor \& Francis Group.

3. Acar M.F., Yapicioglu B., Arikan N., Ates N., Ergun M. (2007). Analysis of goals scored in 2006 World Cup. Journal of Sport Science \& Medicine, Book of Abstracts 6(Supl. 10), 3-4.

4. Armatas V., Yiannakos A., Sileloglou P. (2007). Relationship between time and goal scoring in soccer games: Analysis of 
three World Cups. International Journal of Performance Analysis in Sport 7(2), 48-58 (11)

5. Martinez L.C., Lago-Ballesteros J. (2007). Analysis of offensive playing patterns in soccer. Journal of Sport Science \& Medicine, Book of Abstracts 6(Supl. 10), 204.

6. Wrzos J. (2005). Polish football players against a background of European and international elite players. Sport Wyczynowy 3-4, 28-47. [in Polish]

7. Wrzos J. (2006). Big football. Poznań: G\&P, Oficyna Wydawnicza. [in Polish]

8. Bergier J., Buraczewski T. (2007). Analysis of successful scoring situations in football matches. Journal of Sport Science $\&$ Medicine, Book of Abstracts 6(Supl. 10), 203.

9. Buraczewski T. (2009). Differences in effectiveness in performing selected ball-play actions by Polish teams and the best teams of the $12^{\text {th }}$ World Cup (South Korea-Japan, 2002). Polish Journal of Sport and Tourism 16(1), 33-38. [in Polish]

10. Duda H. (2008). Intellectualization of the education process and the development of a disposition for sports (a football case study). Studia i Monografie 50, Kraków: AWF Kraków. [in Polish]

11. Szwarc A. (2002). A method for assessing football players' technical and tactical actions. Sport Wyczynowy 7-8, 21-32. [in Polish]

12. Szwarc A. (2004). Differences in player effectiveness among football teams with the highest professional rankings. $W_{y-}$ chowanie Fizyczne i Sport 48, 141-148. [in Polish]

13. Buraczewski T. (2006). Differentiated analysis of the playing structure of football players from Brazil as compared to their rivals at the 2002 World Cup. Rocznik Naukowy ZWWF Biała Podlaska 13, 7-15. [in Polish]

14. Szwarc A. (2003). Technical and tactical assessment methods for actions by football players. Gdańsk: AWFiS Gdańsk. [in Polish]

Submitted: July 26, 2013

Accepted: August 23, 2013 